\title{
The role of exfoliative cytology and molecular biology in oral potentially malignant disorders
}

\author{
Ravi Teja Chitturi, Elanagai Rathinam', Rochard Santo², Thukanayakanpalayam Ragunathan Yoithapprabhunath ${ }^{3}$ \\ Basic Health Sciences Unit, School of Dentistry, Faculty of Medical Sciences, The University of the West Indies, St. Augustine, Trinidad and \\ Tobago, ${ }^{1}$ Department of Paediatric Dentistry and Special Care, PAECOMEDIS Research Cluster, Ghent University, Ghent, Belgium, ${ }^{2}$ Oral \\ Diseases Unit, School of Dentistry, Faculty of Medical Sciences, The University of the West Indies, St. Augustine, Trinidad and Tobago, \\ Caribbean, ${ }^{3}$ Department of Oral and Maxillofacial Pathology, Vivekanandha Dental College for Women, Elaiyampalayam, Tamil Nadu, India
}

Received: 15-02-17

Accepted: 03-04-17

Published: 15-06-17

\section{ABSTRACT}

According to the latest statistics, oral squamous cell carcinoma is the $9^{\text {th }}$ most common cancer to diagnose worldwide, especially in males and in the developing countries and cause for high mortality and morbidity. Oral potentially malignant disorders (OPMD's) are an important entity associated as precusors for most of these cases which are reversible. Hence, early detection of OPMD's can be very useful. Exfoliative cytology is a practically very easy and patient-friendly method to collect cells from these lesions. They can be subjected to a variety of analysis to help us detect oral cancer in advance. This review describes all the techniques have been used in early detection right from the conventional techniques to molecular diagnostics.

Keywords: Early detection, exfoliative cytology, oral cancer, precancer

\section{INTRODUCTION}

Oral squamous cell carcinoma (OSCC) is one of the most dreaded diseases with high rate of mortality and morbidity. According to the latest statistics, it is the $9^{\text {th }}$ most common cancer to diagnosed worldwide, especially in males and in the developing countries. ${ }^{[1]}$ Tobacco in smoking and smokeless forms along with human papilloma virus are the leading cause for OSCC, and recently, it has been found that not only males but also females are at risk for developing OSCC because of the ongoing tobacco epidemic in most of the European countries. In addition, other than tobacco, the presence of microorganisms has also been associated with malignancies. ${ }^{[2-5]}$ Hence, early diagnosis plays an important role

Address for correspondence: Dr. Ravi Teja Chitturi, School of Dentistry, Faculty of Medical Sciences, The University of the West Indies, St. Augustine, Trinidad and Tobago, Caribbean.

E-mail: dr.raviteja@gmail.com

\begin{tabular}{|l|l|}
\hline \multicolumn{2}{|c|}{ Access this article online } \\
\hline Quick Response Code: & Website: \\
\hline & www.jhr.org \\
\cline { 2 - 2 } & \\
\hline & DOI: \\
\hline
\end{tabular}

in the prevention of OSCC-related deaths. Another important entity associated with OSCC is the oral potentially malignant disorders (OPMD's). These disorders are a family of morphological alterations occurring in the oral cavity among which some (oral submucous fibrosis, leukoplakia, oral lichen planus, etc.) may have an increased potential for malignant transformation into OSCC..$^{[6-9]}$ These lesions are the precursor lesions for OSCC and diagnosis of these disorders are of prime importance to prevent malignant transformation as these can be reverted back if intervened correctly. The 5 years survival rate of patients with OSCC is found to be significantly improved when diagnosed early. ${ }^{[10]}$ Although biopsy remains the gold standard for the diagnosis of OPMD's, cytology in recent years has proven more than just an adjuvant for diagnostic purposes. In addition, biopsy is an invasive technique that has surgical implications, a psychological impact on the patient, and technique limitations for professionals. Furthermore, biopsy has limitations in large lesions for which it is important to select the most appropriate site to perform biopsy. ${ }^{[1]}$

This is an open access article distributed under the terms of the Creative Commons Attribution-NonCommercial-ShareAlike 3.0 License, which allows others to remix, tweak, and build upon the work non-commercially, as long as the author is credited and the new creations are licensed under the identical terms.

For reprints contact: reprints@medknow.com

How to cite this article: Chitturi RT, Rathinam E, Santo R, Yoithapprabhunath TR. The role of exfoliative cytology and molecular biology in oral potentially malignant disorders. J Health Res Rev 2017;4:43-6. 
The adjuvant diagnostic techniques for the detection of OPMD's and OSCC include vital staining techniques (Toluidine Blue, Lugol's lodine, Methylene Blue), light-based detection systems (chemiluminescence and autofluorescence), and cytological techniques. ${ }^{[12]}$ In recent years, use of molecular methods has taken a prime place in diagnosis, screening, and follow-up of patients with OPMD's, especially with those with tobacco habits. The basis of high sensitivity and specificity for these techniques is because the changes that occur during dysplasia and OSCC are first evident at a molecular level rather than a cellular level. In this regard, exfoliative cytology has also played a significant role because of its numerous advantages such as easy to perform and noninvasive method of sample collection, easily acceptable for the patient, and an apt technique for mass screening and follow-up. ${ }^{[13]}$ This article describes the various cytological and molecular techniques that can be used for early detection of OPMD's.

The first step involved in cytology is the collection and preparation of smears. There are two techniques involved. Although the collection of the smears may be same the preparation of smears is different. The two techniques are,

a. Conventional technique

b. Liquid-based cytology.

\section{CONVENTIONAL TECHNIQUES}

Conventionally, the use of exfoliative cytology for the diagnosis of uterine cancer was first described by Papanicolaou after whom the technique and stain (PAP stain) is named. ${ }^{[14,15]}$ This staining technique has been used with success in the detection of uterine cancer but its applicability as far as oral cancer is concerned has been as an adjuvant only. The detection of cells is primarily based on the stain, the cells take up which correlates with degree of maturation of the cell. The failure of this staining technique in relation to lesions of the oral cavity is due to the high false rates and due to the absence of a squamocolumnar junction in the oral cavity. Various sample collection devices have been used to improve the accuracy of this technique. Use of wooden spatula and brush has been traditionally used in this technique. The use of brush (transepithelial biopsy) over conventional cytology is advantageous because the cells can be collected from all the layers in the oral epithelium. Inspite of these devices, the use of this stain has limited application in the oral cavity because of the oral topography, and the size of the oral cavity makes it impossible to examine the entire mucosal surface. Another important reason is the oral mucosa being more fibrotic which prevents exfoliation of the dysplastic cells to the epithelial surface. ${ }^{[16]}$ The presence of a thick keratin layer on the oral epithelium when compared to the uterine cervix also presents a challenge to the identification of dysplastic cells. Using these collecting methods, the smears are transferred to a glass slide by evenly spreading on a glass slide, fixing them using alcohol, and staining them. This method has several disadvantages and limitations such as improper cellular distribution and overlapping of cells, varied thickness, folding of cells, and presence of impurities in the smear. To overcome all these problems, liquid-based cytology was introduced. ${ }^{[17]}$

\section{LIQUID-BASED CYTOLOGY}

Introduction of liquid-based cytology to prepare a smear improved the cellular distribution and thickness. Some of the advantages included it being a less time-consuming method and also the smears showed better cytological morphology. ${ }^{[17]}$ This technique although was first applied to cervical cancer now has been studied for screening of oral cancer as well. It is considered to be cost-effective method, and at the same time, the cells were seen in a clearer background and also the smears have a longer storage time. ${ }^{[18,19]}$ In this technique, after collecting the cells, the cells are first suspended in a suitable fixative (preservative) medium. Then, it is centrifuged, and a smear is prepared. Recently, automated machines which perform a filtration process followed by a computer-assisted thin layer deposition of cells have been developed as a replacement for manual cytocentrifugation. This technique is expensive. ${ }^{[20]}$

\section{ANALYSIS OF SMEARS}

The next important step is the analysis of smears. The application of smears is varied, and different analytical methods are used according to the need. The various analytical methods include

i. Cytomorphometry

ii. DNA Image cytometry (DIC)

iii. Automated Systems

iv. Molecular Analysis.

\section{CYTOMORPHOMETRY}

Cytomorphometry is a technique that is used to measure the size of the cell and nucleus to determine whether the cell is turning malignant or not. The indicators include a reduced cell diameter and an increased nuclear diameter. This technique has been used by various authors using different stains and have shown that it is a reliable indicator of these changes. ${ }^{[1-23]}$ Although this method was reliable and used computers for assessment, the development of completely automated systems took a lot of time. The development of automated systems became important because visual screening became not only very demanding but also tedious and expensive as well in terms of manual labor requirements. The use of automated systems has been used not only with cytomorphometry but also along with cytometry which has been described in the next section.

\section{DNA IMAGE CYTOMETRY}

DIC is based on the concept of detecting the ploidy status of the DNA in the nucleus to detect for premalignancy and is considered to be better than the above-mentioned analysis methods. ${ }^{[24]}$ In the conventional technique and cytomorphometry, PAP stain is considered to provide the highest sensitivity and specificity. However, for this technique, the use of Feulgen stain is recommended compared to PAP or routine hematoxylin and eosin stains. ${ }^{[25]}$ This is because this stain ensures that the staining intensity of the nucleus is in proportion to the amount of DNA present. As it is a stoichiometric procedure, each fixed molecule of Schiff's reagent correlates to an equivalent portion of the DNA. ${ }^{[26]}$ Various studies have been done to test the sensitivity and specificity of this method of analysis. The application of automated systems which combine the techniques mentioned so far is essential. 


\section{AUTOMATED SYSTEMS}

One of the first systems that brought about the detection of oral premalignant lesions was the oral CDx. The results were classified as "negative," "atypical," and "positive."[27] Some of the other first generation systems included the Cytoanalyzer which took into account not only the nuclear size but also the nuclear density. Various other automated systems were developed in Japan and Britain which basically reduced the pixel size detection for improved accuracy. ${ }^{[28]}$ As technology advanced, the later image analysis systems used higher resolution images to analyze the above-mentioned features to obtain a better focus. Further, systems that developed a smear automatically were developed which integrated the use of liquid-based cytology. ${ }^{[29,30]}$ The automated systems that were developed after this used a dual resolution system where the first resolution was used to scan the slide, and the higher magnification was used to analyze the cells. They used the systems where the results were either 'normal' or 'requires inspection' based on the systems analysis using mathematical formulas. ${ }^{[28]}$

\section{MOLECULAR ANALYSIS}

With recent advancements in molecular techniques, the accuracy in detection of malignant changes has advanced rapidly in the field of exfoliative cytology. Gupta et al. used cytokeratin 8 and 19 in smears of patients with OSCC and found that in combination with DIC improved accuracy in cancer detection. ${ }^{[31]}$ Other immunocytochemical makers that have been successfully used for the detection of OPMD's are laminin 5, high molecular weight tenascin-C, and few extracellular matrix components. ${ }^{[32-34]}$ The use of microsatellite analysis and RNA evaluation using reverse transcription polymerase chain reaction of various cancer expression genes in brush biopsy has also been very successful. ${ }^{[35-37]}$ The use of nano-biochip systems with tumor markers such as epidermal growth factor receptor has also been recently published. ${ }^{[38]}$ Detection of cancer markers using fluorescent techniques is also becoming fairly popular in the recent years. The use of fluorescent dyes to detect DNA aneuploidy and use of fluorescent in situ hybridization has been successfully employed over the last decade in cytological samples. ${ }^{[39,40]}$ Application of proteomics, Chromosome in situ hybridization, ProteinChip Arrays (SELDI), and gene microarray have significantly improved the sensitivity and specificity as well accuracy in exfoliative cytology. Recently, few authors have combined all the techniques mentioned above right from cellular detection of atypical cells to molecular methods described in this section of stratify the risk of oral leukoplakic patients using expert-guided data transformation and reconstruction and support vector machine. ${ }^{[41,42]}$ Application of Raman spectroscopy in early detection of oral cancer using exfoliative cytology has also been recently reported. ${ }^{[43]}$

\section{CONCLUSION}

For all these years, the use of exfoliative cytology has been of importance only in the detection of cervical cancer whereas in oral cancer, and precancer detection, it has been only an adjuvant because of its unreliability. However, recent advances in molecular methods combined with the practical advantages of exfoliative cytology can be really useful for early detection of OPMD's.

\section{Financial support and sponsorship}

Nil.

\section{Conflicts of interest}

There are no conflicts of interest.

\section{REFERENCES}

1. Jemal A, Bray F, Center MM, Ferlay J, Ward E, Forman D. Global cancer statistics. CA Cancer J Clin 2011;61:69-90.

2. Prasad LK. Burden of oral cancer: An Indian scenario. J Orofac Sci 2014;6:77.

3. Verma R, Singh A, Badni M, Chandra A, Gupta S, Verma R. Evaluation of exfoliative cytology in the diagnosis of oral premalignant and malignant lesions: A cytomorphometric analysis. Dent Res J (Isfahan) 2015;12:83-8.

4. Garavello W, Bertuccio P, Levi F, Lucchini F, Bosetti C, Malvezzi M, et al. The oral cancer epidemic in central and eastern Europe. Int J Cancer 2010;127:160-71.

5. Kaja SL, Kattappagari KK, Chitturi R, Prashanth L, Reddy BV. Helicobacter pylori and its orodental implications: A review. J NTR Univ Health Sci 2015;4:203-8.

6. Warnakulasuriya S, Johnson NW, van der Waal I. Nomenclature and classification of potentially malignant disorders of the oral mucosa. J Oral Pathol Med 2007;36:575-80.

7. Chitturi RT, Sindhuja P, Parameswar RA, Nirmal RM, Reddy BV, Dineshshankar J, et al. A clinical study on oral lichen planus with special emphasis on hyperpigmentation. J Pharm Bioallied Sci 2015;7 Suppl 2:S495-8.

8. Chitturi RT, Kumar VA, Naik P, Kattimani V. Oral submucous fibrosis - An Indian perspective. Research 2014;1:702.

9. Chitturi RT, Devy AS, Nirmal RM, Sunil PM. Oral lichen planus: A review of etiopathogenesis, clinical, histological and treatment aspects. J Interdiscip Med Dent Sci 2014;2:142.

10. Alok A, Singh S, Singh ID, Kishore M. Early detection of precancerous and cancerous lesion. Univ Res J Dent 2016;6:10-4.

11. Shwetha KN, Vanishri HC, Dominic A, Sowmya SV, Roopa RS. Recent advances in diagnosis of oral cancer. J Dent Orofac Res 2016;1:19-21.

12. Reddy GS, Rao KE, Kumar KK, Sekhar PC, Prakash Chandra KL, Ramana Reddy BV. Diagnosis of oral cancer: The past and present. J Orofac Sci 2014;6:10-6.

13. Kazanowska K, Hałoń A, Radwan-Oczko M. The role and application of exfoliative cytology in the diagnosis of oral mucosa pathology Contemporary knowledge with review of the literature. Adv Clin Exp Med 2014;2:299-305.

14. Papanicolaou GN, Traut HF. Diagnosis of Uterine Cancer by the Vaginal Smear. New York: The Commonwealth Fund; 1943. p. S1-47.

15. Papanicolaou GN. A survey of the actualities and potentialities of exfoliative cytology in cancer diagnosis. Ann Intern Med 1949;31:661-74.

16. Mehrotra R. The role of cytology in oral lesions: A review of recent improvements. Diagn Cytopathol 2012;40:73-83.

17. Singh VB, Gupta N, Nijhawan R, Srinivasan R, Suri V, Rajwanshi A Liquid-based cytology versus conventional cytology for evaluation of cervical pap smears: Experience from the first 1000 split samples. Indian J Pathol Microbiol 2015;58:17-21.

18. Dwivedi N, Agarwal A, Raj V, Kashyap B, Chandra S. Comparison of centrifuged liquid based cytology method with conventional brush cytology in oral lesions. Eur J Gen Dent 2012;1:192-6.

19. Shukla S, Einstein A, Shukla A, Mishra D. Comparison of specimen adequacy and smear quality in oral smears prepared by manual liquidbased cytology and conventional methods. J Oral Maxillofac Pathol 2015;19:315-8.

20. Ahmed HG, Edris AM, Mohmed EA, Hussein MO. Value of centrifugated liquid-based cytology by Papanicolaou and May-Grünwald in oral epithelial cells. Rare Tumors 2009;1:e12.

21. Metgud R, Gupta K, Prasad U, Gupta J. Cytomorphometric analysis of oral submucous fibrosis and leukoplakia using methyl green-pyronin Y, Feulgen staining and exfoliative brush cytology. Biotech Histochem 2015;90:8-13 
22. Teja CS, Devy AS, Nirmal RM, Sunil PM, Deepasree M. Cytomorphometric analysis of exfoliated cells in oral lichen planus. Cytojournal 2014;11:3.

23. Nivia M, Sunil SN, Rathy R, Anilkumar TV. Comparative cytomorphometric analysis of oral mucosal cells in normal, tobacco users, oral leukoplakia and oral squamous cell carcinoma. J Cytol 2015;32:253-60.

24. Abt E. DNA-image cytometry has promise for oral cancer detection. Evid Based Dent 2015;16:106-7.

25. Duarte CE, Carvalho CR, Silva-Filho AL. Adaptation of image cytometry methodology for DNA ploidy analysis of cervical epithelium samples: A pilot study. Taiwan J Obstet Gynecol 2014;53:227-31.

26. Chitturi RT, Nirmal RM, Sunil PM, Devy AS, Reddy BV. Evaluation of ploidy status using DNA-image cytometry of exfoliated mucosal cells in oral lichen planus. J Cytol 2014;31:131-5.

27. Trakroo A, Sunil MK, Trivedi A, Garg R, Kulkarni A, Arora S. Efficacy of oral brush biopsy without computer-assisted analysis in oral premalignant and malignant lesions: A study. J Int Oral Health 2015;7:33-8.

28. Bengtsson E, Malm P. Screening for cervical cancer using automated analysis of PAP-smears. Comput Math Methods Med 2014;2014:842037.

29. Erhardt R, Reinhardt ER, Schlipf W, Bloss WH. FAZYTAN: A system for fast automated cell segmentation, cell image analysis and feature extraction based on TV-image pickup and parallel processing. Anal Quant Cytol 1980;2:25-40.

30. Howell LP, Davis RL, Belk TI, Agdigos R, Lowe J. The AutoCyte preparation system for gynecologic cytology. Acta Cytol 1998;42:171-7.

31. Gupta S, Shah JS, Parikh S, Limbdiwala P, Goel S. Clinical correlative study on early detection of oral cancer and precancerous lesions by modified oral brush biopsy and cytology followed by histopathology. J Cancer Res Ther 2014;10:232-8.

32. Driemel O, Dahse R, Hakim SG, Tsioutsias T, Pistner H, Reichert TE, et al. Laminin-5 immunocytochemistry: A new tool for identifying dysplastic cells in oral brush biopsies. Cytopathology 2007;18:348-55.

33. Driemel O, Dahse R, Berndt A, Pistner H, Hakim SG, Zardi L, et al. High-molecular tenascin-C as an indicator of atypical cells in oral brush biopsies. Clin Oral Investig 2007;11:93-9.

34. Driemel O, Kosmehl H, Rosenhahn J, Berndt A, Reichert TE, Zardi L et al. Expression analysis of extracellular matrix components in brush biopsies of oral lesions. Anticancer Res 2007;27:1565-70.

35. Carreras-Torras C, Gay-Escoda C. Techniques for early diagnosis of oral squamous cell carcinoma: Systematic review. Med Oral Patol Oral Cir Bucal 2015;20:e305-15.

36. Kolokythas A, Zhou Y, Schwartz JL, Adami GR. Similar squamous cell carcinoma epithelium microRNA expression in never smokers and ever smokers. PLoS One 2015;10:e0141695.

37. Kolokythas A, Schwartz JL, Pytynia KB, Panda S, Yao M, Homann B, et al. Analysis of RNA from brush cytology detects changes in B2M CYP1B1 and KRT17 levels with OSCC in tobacco users. Oral Oncol 2011;47:532-6

38. Omar E. Current concepts and future of noninvasive procedures for diagnosing oral squamous cell carcinoma - A systematic review. Head Face Med 2015;11:6.

39. Palka KT, Slebos RJ, Chung CH. Update on molecular diagnostic tests in head and neck cancer. Semin Oncol 2008;35:198-210.

40. Shashikala R, Indira AP, Manjunath GS, Rao KA, Akshatha BK. Role of micronucleus in oral exfoliative cytology. J Pharm Bioallied Sci 2015;7 Suppl 2:S409-13.

41. Ahmed SM, Mubeen, Jigna VR. Molecular biology: An early detector of oral cancers. Ann Diagn Pathol 2009;13:140-5.

42. Liu Y, Li J, Liu X, Liu X, Khawar W, Zhang X, et al. Quantitative risk stratification of oral leukoplakia with exfoliative cytology. PLoS One 2015;10:e126760.

43. Sahu A, Tawde S, Pai V, Gera P, Chaturvedi P, Nair S, et al. Raman spectroscopy and cytopathology of oral exfoliated cells for oral cancer diagnosis. Anal Methods 2015;7:7548-59. 